University for Business and Technology in Kosovo

UBT Knowledge Center

UBT International Conference

2015 UBT International Conference

Nov 7th, 9:00 AM - 5:00 PM

\title{
Opportunities for investments in Kosovo
}

Besnik Avdiaj

University of Prishtina, besnikavdiaj@hotmail.com

Follow this and additional works at: https://knowledgecenter.ubt-uni.net/conference

Part of the Business Commons

\section{Recommended Citation}

Avdiaj, Besnik, "Opportunities for investments in Kosovo" (2015). UBT International Conference. 26.

https://knowledgecenter.ubt-uni.net/conference/2015/all-events/26

This Event is brought to you for free and open access by the Publication and Journals at UBT Knowledge Center. It has been accepted for inclusion in UBT International Conference by an authorized administrator of UBT Knowledge Center. For more information, please contact knowledge.center@ubt-uni.net. 


\title{
Opportunities for investments in Kosovo
}

\author{
Besnik Avdiaj \\ University of Prishtina, "Hasan Prishtina", in Prishtina, Republic of Kosovo, Faculty of \\ Economics, Department of Management and Informatics. \\ besnikavdiaj@hotmail.com
}

\begin{abstract}
Kosovo, as a new state in the region and Europe, has a relatively new, with serious allegations towards achieving upward-trend sustainability. After a deep transformation from a centralized economy, in an open market economy, with all the destruction made during the war, Kosovo has managed to create the basis for economic development, in parallel with regional developments. Goals that the relevant institutions have set themselves about the economy, related to enhancing the competitiveness of the economy on the regional, European and global trade, by reducing trade deficit, increasing exports, absorption of the foreign direct investments, membership in regional and global organizations, by being already a member of CEFTA, IMF, World Bank, EBRD, ECB and aspires to the WTO. As a new country for business development, facing all the current challenges, Kosovo offers numerous opportunities and a wide range of business activities, such in agriculture, tourism, viticulture, extraction and processing of metals, technological innovation, food industry, etc. But particularly, it is worth mentioning great opportunities for economic development, which are linked with many natural resources owned by Kosovo, then a relatively young age workforce, with an average age of about 30 , suitable climatic conditions, very favorable fiscal policy, where taxes are the lowest in the region, the geographical position, which makes Kosovo a regional economic crossroad, modern institutions in supporting business, the euro, which avoids the risk of the Eurozone and financial stability, assisted in particular by the IMF. With these features, Kosovo represents an ideal model, which can be used in the best way for investment. However, the relevant institutions should work further to promote investment opportunities in parallel with overcoming the challenges that are damaging the image of the state.
\end{abstract}

Keywords: Economic development, investments, opportunities, resources

\section{Introduction: Kosova's economy in general terms}

Kosova is a new country, which lies in the heart of the Western Balkans, thus becoming a bridge between the countries that make up this region. It is bordered by Albania, Montenegro, Serbia and Macedonia, and so is a crossroads through which pass the roads with economic and development importance. The Republic of Kosova has declared its independence on 17 February 2008, thus becoming the youngest sovereign state in the continent of Europe. With this act, the people of Kosova eventually declared willingness to move forward relying on its own forces and signaled the international community's the determination to create independent state structures and work on their consolidation even further, so that all residents of Kosova to feel equal and have better standards of living than in the past. So, with the political and legal changes, Kosova entered a new phase of economic development, making the country to incur deep transformations in one of the basic pillars of the functioning of a state: the economy.

Today, Kosova's economy is characterized by great achievements in many areas, yet it faces ongoing wide-variety challenges. Responsible institutions constantly work to overcome them and achieve their ambitious goals.

\subsection{The transformation}

History of Kosova's economy does not begin with the declaration of independence. It goes much earlier in history, but the closest period to our days is the socialist system of the former Yugoslavia, 
part of which was Kosova. Although Kosova has served as an important economic resource of the former Yugoslavia, the war and poor governance of the UN mission in Kosova, brought the country's economy in the state of collapse.

Shortly after 1990, concretely after the reoccupation of Kosova from Serbia, the political, social and economic situation, sharpened even more and after that year could not be talked any more about the normal course of life in Kosova. Demolition of the economy started with high intensity. [3]

For nine years during the 90s, Kosova set up a parallel system of functioning of the economy and other institutions, becoming a huge market not only for the people and local customers, but also to neighboring countries. Therefore, the Serbian state, under the Milosevic regime, intervened committing robbery and impoverishing the people. People found themselves without a clear perspective. [1] But after the 1998-1999 war, Kosova emerged with enormous human and material damages, and was put under international protection by the resolution 1244 of the UN Security Council. Broadly, the transition period can be defined as a transition from a statist and bureaucratic society with an autocratic regime of one party in a democratic society with political pluralism, as well as crossing from the directed economy with plans to the market economy and pluralism of the property. [3] So there began to be created opportunities to free economy, export and import of products, raising the standard of residents' lives and the prospects for development.

\subsection{Until-now achievements}

Kosova's economy has not achieved a strong consolidation yet, but the steps made so far are on the direction of stability and constant growth. It has built strong premises for economic development, although many setbacks continue to be present. The achievements are characterized by a low level of development, with an unfavorable economic structure, from an irrational business, lack of experience and impossibilities of applying marketing in development strategy, etc. [3]

However, among many achievements, it is worth mentioning the membership of Kosova in regional and international economic organizations. So, in 2007 it became a member of CEFTA (Central European Free Trade Agreement), having duty-free access to a market of 30 million consumers. In 2009 it joined the International Monetary Fund and World Bank, and later to the European Bank for Reconstruction and Development, absorbing new investments in infrastructure, financial stability and macroeconomic stability. Kosova has strong tendencies to join the World Trade Organization.

On the other hand, when the region was affected by the global crisis, Kosova's economy continued to maintain upward trend, bringing about 3-4\%. However it shows that the role in the global economy is extremely small. Also, Kosova is ranked the 98th in the Index of Doing Business of World Bank, [10] marking a steady increase in creating opportunities and facilitating the procedures for doing business in the country, as well as it has increased obviously the absorption of remittances from abroad, which increased is about $11.7 \%$ in 2014, or 693 million euros. [2]

\subsection{Challenges}

Despite the achievements, the domestic economy is facing many challenges. Among them is the unemployment, particularly that among the youth.

Kosova remains one of the countries that face one of the highest unemployment rates in Europe. As a result, many spheres of life have continually stalled and are facing difficulties. In the figure below, according to the Kosova Agency of Statistics, can be seen the variability in the unemployment rate in the years 2012-2014. 


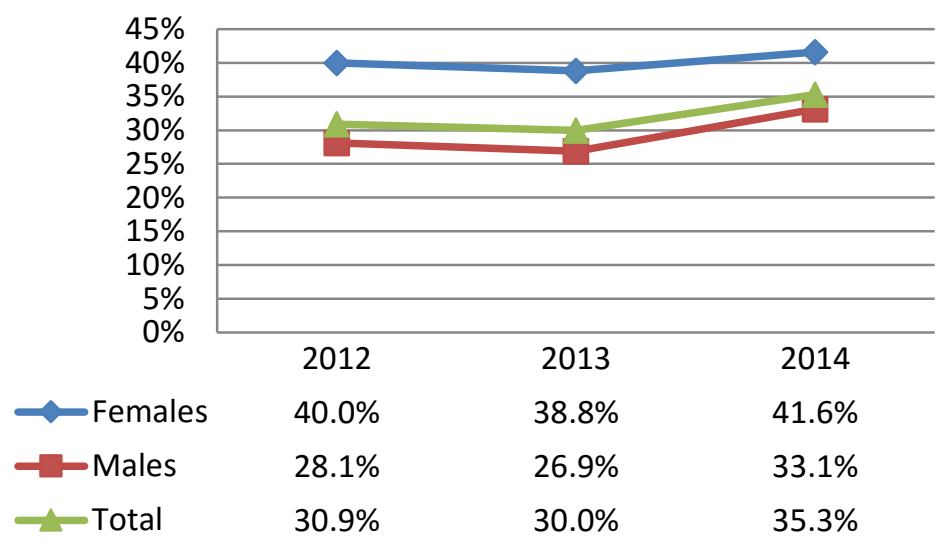

Figure 1. Rate of unemployment 2012-2014. Source: Kosova Agency of Statistics [5]

Since it is known that Kosova has a large dependence on foreign investment, increasing the FDIs, appears to be a strong challenge.

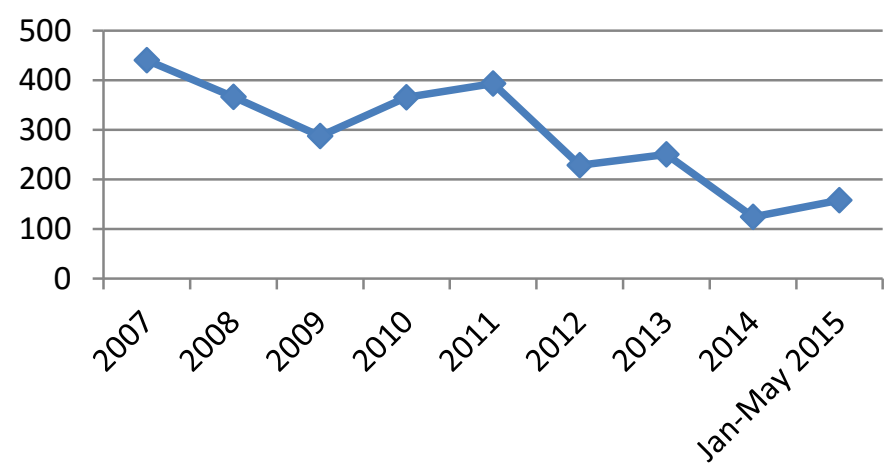

Figure 2. Foreign Direct Investments (million $€$ ) in Kosova during the period 2007 May 2015. Source: Central Bank of Kosova

For the countries emerging from war, in transformation phase, an important role plays the importation of products to cover consumer demand. At the same time this is hurting local producers, increasing deficit between trade exchanges. According to the Kosova Agency of Statistics, Kosova's trade deficit in July of 2014 was 203.6 million euros. Exports in the month covered imports by $14.3 \%$, while in February 2014 by $14.2 \%$, marking off 0.1 percentage points. [6]

The high interest rates hinder business activities, but in 2015, Kosova has increased the trend of interest rate cuts, down to single digits.

According to the classical theory on economic development, the investment strategy is based on capitalizing the favorable factors and eliminating the restrictive factors of a country. [3] Therefore the creation of premises needed for economic development through investment and using the resources owned by Kosova, then It will come up to the elimination of the restrictive factors.

\section{Opportunities for investments}

Despite the achievements, setbacks and challenges the economy is facing, Kosova offers a wide range of opportunities to make investments. Even taking into account all the negative factors affecting the attraction of investors, yet the country is heading towards the creation of basic conditions and climate for doing business without fear of failure. So, relying on the geographical position of the country, 
sources with large capacity, financial stability and favorable economic policies and the potential business activities, Kosova appears to be a perfect model to be used by foreign investors.

\subsection{Geographical position}

Republic of Kosova lies in Southeastern Europe, specifically in the region of Western Balkans. With an area of $10,908 \mathrm{~km}^{2}$, Kosova takes a central place in this region, becoming the crossroads of important traffic routes. With the geostrategic position, Kosova had an important role in the former Yugoslavia, not only connecting different parts of the country, but with special emphasis should be assessed the natural connections through the valleys of mountain-necks with neighboring countries. [9] As a result of this favorable position, Kosova's capital, Pristina has the distance from the neighbor large centers as follows: $90 \mathrm{~km}$ from Skopje, $120 \mathrm{~km}$ from Nis, about $200 \mathrm{~km}$ from Sofia, about 300 $\mathrm{km}$ from Tirana and Belgrade, $350 \mathrm{~km}$ from Thessaloniki, while a little farther from Podgorica and Sarajevo. However, through the capital investments in infrastructure, Kosova is linked by highway to Tirana, but is expected to be connected soon to Nis, Skopje and Ulcinj. Thus, the traffic network only increases the importance of the geographical position of Kosova, and as a result creates an important premise for economic development.

\subsection{Resources}

First of all, it should be known that Kosova is not an economic burden to anyone, because it has enough development potential, based on its strength. [3]

It has the youngest workforce in the region and Europe, where according to statistics, about $70 \%$ are under 35 years old, and according to a study by the Ministry of Culture, Youth and Sports, published in the form of a strategy for youth development in 2013, it is estimated that in the next five years, an average of 200,000 young people will reach working age and approximately 110,000 of them will enter the labor market. [8]

In terms of natural resources that the country possesses, the most important are: coal, zinc, lead, ferronickel and many fertile lands. More accurately, Kosova is the second largest reserves of coal in Europe, and ranks the fifth worldwide with over 12 billion tons of lignite. Kosova has also Trepça Mine, which is considered as one of the mines with the largest capacities of minerals in Europe.

Kosova possesses an area of nearly 1.1 million hectares, of which about $53 \%$ is agricultural area, $41 \%$ forests and $6 \%$ other types. 193,000 ha of agricultural land is used for crops, like pastures 166,000, and 124,000 ha of meadows and other crops. With about 1 million various animals species and 45,000 beehives, Kosova represents a tremendous potential for the development of livestock. [7]

As important resources are also considered around 1000 touristic destinations, all over Kosova. Rugova Mountains region, Sharr Mountains, Morava, Kopaonik, are among others the potential tourist destinations. And also health tourism, the cultural, religious and historical, lakes, rivers, gorges, canyons, caves, etc., [9] represent a great opportunity, which with only a few infrastructure investment and promotion, can succeed in attracting foreign visitors.

\subsection{Financial stability and economy policies}

The country is characterized by financial stability and inflation control. The IMF's is supervisory and consultant in the development of this field, putting pressure on economic policy makers to maintain the financial stability. Even the external debt is low, although there is an increase of about eight percentage points if compared with 2013. The 2014 it represents $31.7 \%$ of GDP, most of which (about $80 \%$ ) in the private debt, and less than $20 \%$ public sector. [4]

Economic policies enable investments, especially the capital, to have different favors, ranging from taxes, then subsidy incentives, etc. Kosova with the government's decision entered into force on September $1^{\text {st }} 2015$, has dropped to $8 \%$ VAT for 13 basic products, but has increased from $16 \%$ to $18 \%$ VAT on other products. This change is being seen critically by some experts of the economy, but on the other hand, according to the government, after the changes made in the customs system, has been made the reduction of customs duties on:

a) Capital Assets (Basic)

b) Raw materials for agribusiness and some other manufacturing sectors 
c) Raw intermediate materials for further processing by $10 \%$ to $0 \%$

\subsection{Business activities}

Kosova offers many opportunities for the selection of business activities. By law, the founders of businesses are enabled to select different versions of legal business activities. Currently trade is the trend, while production and services are scarce. However, Kosova is gradually creating a favorable infrastructure for manufacturing businesses. In particular, the best options that are available today in production as business activities are focused on the development of agriculture as a sector with great potential. But not only that, because knowing that Kosova has a relatively young population, technological innovation and investments in innovative businesses have much more potential to function and increase profitability and market needs. On the other hand, with mineral wealth and power, Kosova provides an extremely attractive model for exploration and exploitation, where large companies, by obtaining governmental permits and licenses, could create numerous employment possibilities and as a result, also increasing citizens welfare and economy.

With the natural resources that can be used for tourism, Kosova also has a great potential for tourism development and as result the bringing foreign money in the country, significantly affecting GDP growth. So, potential investments would be best to be oriented at those areas where the advantages of the profits will be constantly growing.

\section{Conclusions}

Kosova is a relatively new economic model. Although it came out of the last war with damages, Kosova's economy started everything from scratch and many successes have been achieved so far. But the challenges are not missing, making in many ways have many setbacks and obstacles. However, with the ups and downs, achievements and challenges, yet Kosova has a lot to offer to investors. With a stable financial system, member of economic organizations, absorbing foreign investment, modern institutions which are applying facilitating policies for businesses, immeasurable human potential and abundant natural resources, make Kosova a country with multiple opportunities to invest. Consequently, it is worth mentioning in particular business fields of agriculture, technology and innovation, energy, minerals and tourism as areas with importance and great tendency to leading the economic development of Kosova, so the best possibilities for investment are in these areas. Therefore, the negative phenomena in the country, such as unemployment, poverty or low standard of living of the inhabitants of Kosova, will be reduced slowly, turning as the positive effects of the new investments.

\section{References}

1. Bajra, E.: Politiconomy. Blini - Bk, London (2010) 125-140

2. Central Bank of Kosova: The annual report 2014. Prishtina, (2015)

3. Daci, NM, Berisha, S., Zajmi A.: The strategy of economic development. Academy of Sciences and Arts and the Chamber of Commerce of Kosova, Prishtina (2002) 17-114

4. Kiçmari, B., Gjocaj, Z.: Report of macroeconomic developments. Central Bank of Kosova, Prishtina (2015) 47

5. Kosova Agency of Statistics: Results of workforce survey 2014 in Kosova. KAS, Prishtina (2015) 22

6. Kosova Agency of Statistics

7. Ministry of Agriculture, Forestry and Rural Development: Spatial Development Report for the agricultural sector. Provisional Institutions of Self-Government of Kosova, Prishtina (2004) 5-13

8. Ministry of Culture, Youth and Sport, Department of Youth: Kosova Strategy for youth 2013-2017. Prishtina (2013) 83

9. Reçica, F., Millaku, B.: Introduction to tourism. Olymp, Pristina (2014) 257-280

10. World Bank: Doing Business 2013: Smarter Regulations for Small and Medium - Size Enterprises. $10^{\text {th }}$ edition. Washington (2013) 